\title{
Oral Recombinant Methioninase Overcomes Colorectal-cancer Liver Metastasis Resistance to the Combination of 5-Fluorouracil and Oxaliplatinum in a Patient-derived Orthotopic Xenograft Mouse Model
}

\author{
HIROMICHI OSHIRO ${ }^{1,2,3}$, YASUNORI TOME ${ }^{3}$, TASUKU KIYUNA ${ }^{3}$, SANG NAM YOON $^{1,2}$, THINZAR M. LWIN $^{2}$, \\ QINGHONG HAN $^{1}$, YUYING TAN ${ }^{1}$, KENTARO MIYAKE ${ }^{1,2}$, TAKASHI HIGUCHI $^{1,2}$, NORIHIKO SUGISAWA ${ }^{1,2}$, \\ YUKI KATSUYA ${ }^{1,2}$, JUN HO PARK ${ }^{1,2}$, ZHIYING ZANG ${ }^{1}$, SAHAR RAZMJOOEI $^{1}$, MICHAEL BOUVET ${ }^{2}$, \\ BRYAN CLARY ${ }^{2}$, SHREE RAM SINGH ${ }^{4}$, FUMINORI KANAYA ${ }^{3}$, KOTARO NISHIDA ${ }^{3}$ and ROBERT M. HOFFMAN ${ }^{1,2}$ \\ ${ }^{1}$ AntiCancer Inc., San Diego, CA, U.S.A.; \\ ${ }^{2}$ Department of Surgery, University of California, San Diego, CA, U.S.A.; \\ ${ }^{3}$ Department of Orthopedic Surgery, Graduate School of Medicine, University of the Ryukyus, Okinawa, Japan; \\ ${ }^{4}$ Basic Research Laboratory, National Cancer Institute, Frederick, MD, U.S.A.
}

\begin{abstract}
Background/Aim: Liver metastasis in colorectalcancer is a recalcitrant disease. To develop precision individualized therapy of this disease, we developed a patientderived orthotopic xenograft (PDOX) model of colorectalcancer liver metastasis. In the present report, we evaluated the efficacy of oral recombinant methioninase (o-rMETase) in combination with 5-fluorouracil (5-FU) and oxaliplatinum (OXA) on the colorectal-cancer liver metastasis PDOX mouse model. Materials and Methods: Colorectal-cancer liver metastasis PDOX models were randomized into three groups of seven mice. Group 1, untreated control with phosphate buffered saline (PBS); Group 2, treated with 5-FU + OXA; and Group 3, treated with 5-FU + OXA + o-rMETase. Results: The colorectal-cancer liver metastasis PDOX model was resistant to $5-F U+O X A(p=0.83$ at day 15 of treatment,
\end{abstract}

Correspondence to: Robert M. Hoffman, Ph.D., AntiCancer, Inc., 7917 Ostrow Street, San Diego, CA 92111, U.S.A. Tel: +1 8586542555, Fax: +1 8582684175, e-mail: all@anticancer.com; Yasunori Tome, MD, Ph.D., Department of Orthopedic Surgery, Graduate School of Medicine, University of the Ryukyus, Okinawa, Japan. Tel: +81 9097883017, e-mail: yash_toume@hotmail.com; Michael Bouvet, MD, Ph.D., Department of Surgery, University of California San Diego Moores Cancer Center, 3855 Health Sciences Drive, \#0987, La Jolla, CA 92093-0987, U.S.A. Tel: +1 8588226191, e-mail: mbouvet@ucsd.edu; Shree Ram Singh,Ph.D., Basic Research Laboratory, National Cancer Institute, Frederick, MD 21702, U.S.A. Tel: +1 3018467331, e-mail: singhshr@mail.nih.gov

Key Words: Patient derived orthotopic xenograft (PDOX), nude mouse, colorectal-cancer liver metastasis, oral recombinant methioninase, 5-fluorouracil, oxaliplatin, resistance.
Group 2). In contrast, the colorectal-cancer liver metastasis PDOX model was arrested by o-rMETase combined with 5$F U+O X A(p<0.01$ at day 15, Group 3). No significant bodyweight differences were observed among the groups. Conclusion: The combination therapy of 5-FU and OXA with o-rMETase can overcome the resistance of first line drugs for colorectal-cancer liver metastasis.

The liver is the most common site of metastases for colorectal cancer. The patients who have unresectable metastases are treated by chemotherapy and have a poor outcome (1-3).

We developed a patient-derived orthotopic xenograft (PDOX) nude mouse model for all major cancers (4). PDOX models are especially valuable to identify effective drugs for individual patients and for identification of transformational novel agents.

Cancer cells are more dependent on methionine (MET) compared to normal cells (methionine dependence/methionine addiction) (5). MET dependence may be the only known general metabolic defect in cancer $(5,6)$. MET restriction (MR) arrests cancer cells selectively in the $S / G_{2}$-phase of the cell cycle (7-9). MET dependence is due to excess use of MET by cancer cells for transmethylation reactions $(5,10,11)$. The excess use of MET in cancer is observed in the very strong signal of $\left[{ }^{11} \mathrm{C}\right]$ MET positron emission tomography imaging and has been termed the "Hoffman effect" analogous to the Warburg effect for glucose (12).

Recombinant methioninase (rMETase), a Pseudomonas putida enzyme cloned in E. coli, has been developed to arrest MET dependent cancer cells $(13,14)$. We have previously shown that rMETase is highly effective on melanoma, pancreatic cancer and sarcoma PDOX models (15-18). Oral 


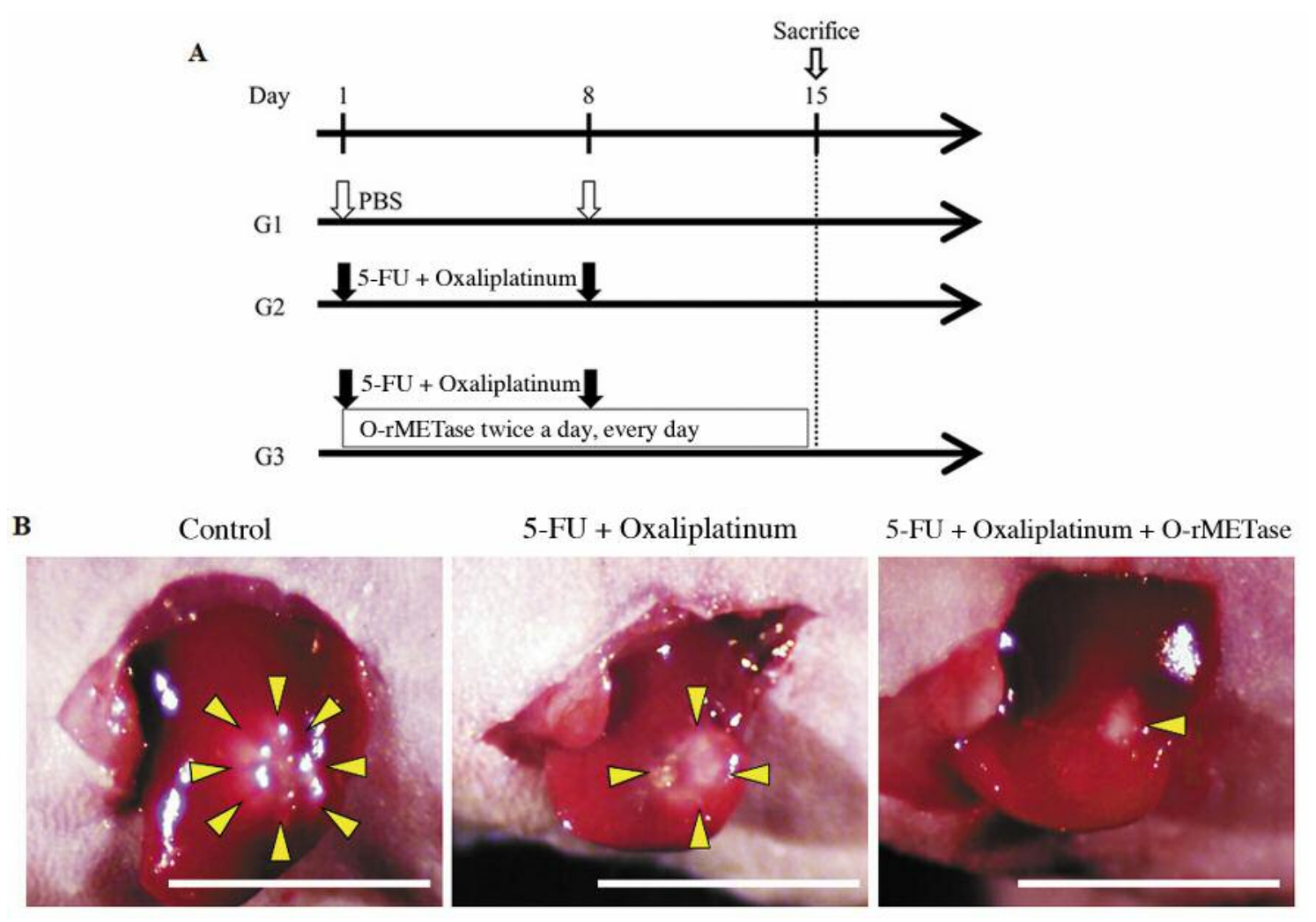

Figure 1. Treatment schema. (A) A patient colorectal-cancer liver metastasis was grown orthotopically in the liver of nude mice. Treatment started on day 1st and ended on day 14th. Group 1, untreated control with PBS, i.p. (n=7); Group 2, treated with fluorouracil (5-FU) + oxaliplatin $\mu$ m (OXA) (5-FU $50 \mathrm{mg} / \mathrm{kg}$, i.p., weekly for 2 weeks, OXA $2 \mathrm{mg} / \mathrm{kg}$, i.p., weekly for 2 weeks) (n=7); Group 3, treated with 5-FU + OXA + oral recombinant methioninase (o-rMETase) (50 unit time, twice a day, oral gavage, daily for 2 weeks) $(n=7)$. ( $B$ ) Images of the untreated and treated colorectal-cancer liver metastasis PDOX models. o-rMETase combined with 5-FU + OXA demonstrated strong efficacy on the colorectal-cancer liver-metastasis PDOX model. Scale bars are $10 \mathrm{~mm}$.

rMETase (o-rMETase) was demonstrated to be more effective compared to intra-peritoneal injection of rMETase on a melanoma PDOX model and was also shown to be effective in PDOX models of melanoma, synovial sarcoma and pancreatic cancer (19-22).

In the present report, we evaluated the efficacy of $\mathrm{o}-$ rMETase in combination with 5-fluorouracil (5-FU) and oxaliplatin (OXA) on a drug-resistant colorectal-cancer liver metastasis PDOX model.

\section{Materials and Methods}

Mice. In the present study, we used athymic nu/nu nude mice (AntiCancer Inc., San Diego, CA, USA) between 4-6 weeks old. All animal studies were conducted with an AntiCancer Inc. Institutional Animal Care and Use Committee (IACUC)-protocol specifically approved for this study and in accordance with the principles and procedures outlined in the National Institutes of Health (NIH) Guide for the Care and Use of Animals under Assurance Number A38731. Procedures for housing, handling, anesthesia, feeding, and humane endpoint criteria have been previously described (20-22).
Patient-derived tumor. The tumor was derived from a patient diagnosed with colorectal-cancer liver metastasis, who had received neoadjuvant chemotherapy. The tumor was resected in the Department of Surgery, University of California, San Diego (UCSD). Written informed consent was provided by the patient, and the Institutional Review Board (IRB) of USCD approved this experiment.

Establishment of the colon-cancer liver metastasis PDOX model by surgical orthotopic implantation (SOI). A fresh sample of colorectal-cancer liver metastasis was previously obtained and transported immediately to the laboratory at AntiCancer, Inc., on wet ice. The procedures for tumor tissue fragmentation and its subcutaneously implantation in nude mice have been previously described $(4,20-22)$. Once the subcutaneously-implanted tumors become $10 \mathrm{~mm}$ in diameter (in 4 weeks), they were harvested and cut into small fragments. Anesthesia was given to mice and 1-2 cm skin incision was made on the upper abdomen through the skin, fascia and peritoneum to expose the liver. A $5 \mathrm{~mm}$ incision was made in the left lobe of the liver and a small tumor fragment was placed to establish the PDOX model and the wound was closed as previously described (20-22). 
A

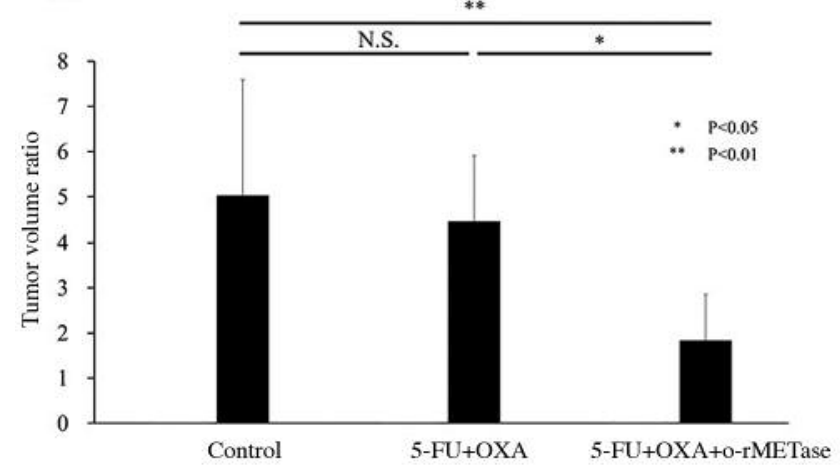

B

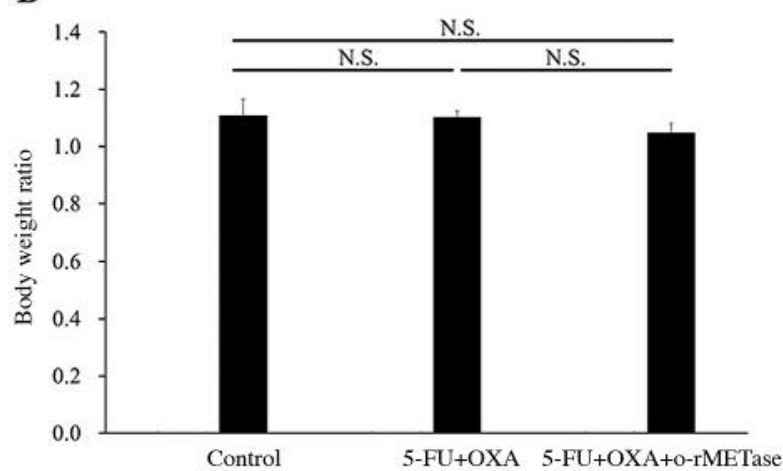

Figure 2. Drug efficacy on tumor volume. Bar graphs show tumor volume ratio (Tumor size on day 15 relative to tumor size at the start of treatment). Error bars show \pm standard deviation. Statistical analysis was performed using Tukey-Kramer test. $* p<0.05$. ** $<<0.01$. (B) Effect of treatment on body weight. Bar graphs show the body weight ratio of mice in each group on 4th day -15 relative to initiation of treatment. Actual body weight: Group 1 (untreated control): $25.41 \pm 2.92$ g; Group 2 (5-FU + OXA): $24.21 \pm 0.97$ g; Group 3 (5-FU + OXA + o-rMETase): $24.40 \pm 2.01$ g.
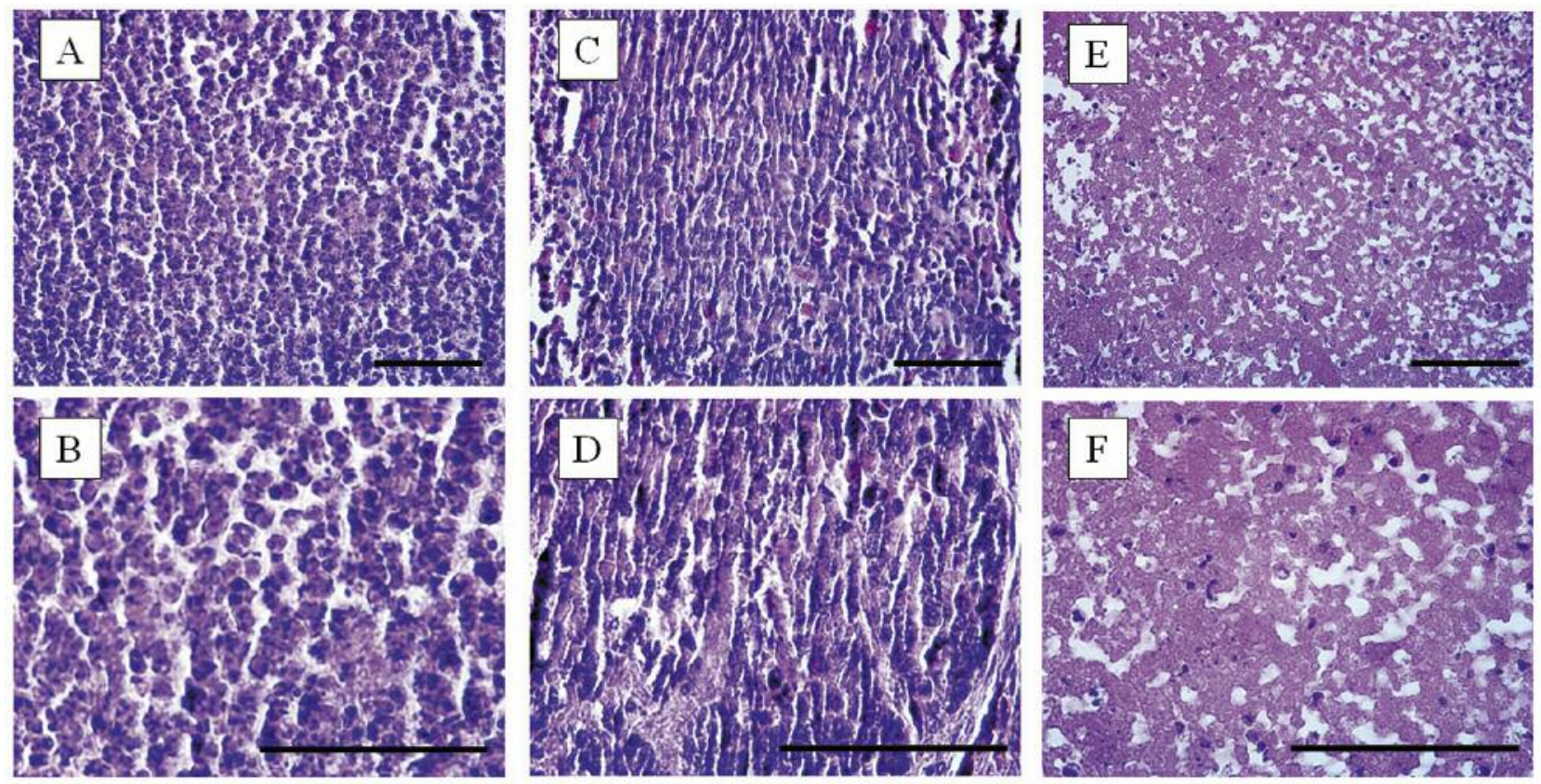

Figure 3. Effect of treatment on tumor histology. (A, B). Untreated control. (C, D) 5-FU + OXA. (E, F) 5-FU + OXA + o-rMETase. Scale bars: $100 \mu$ m.

Recombinant Methionase (rMETase) production. Methods to produce recombinant L-methionine $\alpha$-deamino- $\gamma$-mercaptomethane lyase [recombinant methioninase (rMETase)] have been previously described (13).

Treatment study design for the colon-cancer liver metastasis PDOX model. Colorectal-cancer liver metastasis PDOX models were randomized into three groups of seven mice. Group 1, untreated control with phosphate buffered saline (PBS), i.p. (n=7); Group 2, treated with 5-FU and OXA (5-FU $50 \mathrm{mg} / \mathrm{kg}$, i.p., weekly for 2 weeks, OXA $2 \mathrm{mg} / \mathrm{kg}$, i.p., weekly for 2 weeks) (n=7); Group 3, treated with 5-FU + OXA + o-rMETase (o-rMETase 50 units/time, twice a day, oral gavage, daily for 2 weeks) $(n=7)$. Tumor length and width were measured both before and after treatment via laparotomy. Tumor volume calculation has been previously described (20-22). Data are presented as mean \pm SD. In the colorectal-cancer liver metastasis PDOX model, treatment was evaluated on the tumor volume ratio and pathology. Adverse event were evaluated based on body weight loss.

Statistical analysis. JMP version 13.0 was used for statistical analyses. Significant differences for continuous variables were 
determined using the Tukey-Kramer test. Line graphs expressed average and error bars show \pm standard deviation. A probability value of $p<0.05$ was considered statistically significant.

\section{Results and Discussion}

The treatment schedule for the colorectal-cancer liver metastasis PDOX model is shown in Figure 1A. Coloncancer liver metastasis PDOX models were randomized into three groups of seven mice. Treatment was for 14 days.

Representative tumors in each group are shown in Figure 1B. The time-course change of the tumor volume ratio is shown in Figure 2A. The colorectal-cancer liver metastasis PDOX model was resistant to the combination of 5-FU + OXA [ $p=0.83$ at day 15 after the start of treatment (Group 2)]. In contrast, the colon-cancer liver metastasis PDOX model was arrested by o-rMETase combined with 5-FU + OXA [ $p<0.01$ at day 15 (Group 3)].

No animal deaths in any groups were observed. Moreover, no significant body-weight differences were observed among the groups (Figure 2B). Actual mouse weight at day-15 for all groups were: Group 1 (untreated control): $25.41 \pm 2.92 \mathrm{~g}$; Group 2 (5-FU + OXA): $24.21 \pm 0.97 \mathrm{~g}$; Group 3 (5-FU + OXA + o-rMETase): $24.40 \pm 2.01 \mathrm{~g}$, respectively.

H\&E-staining of tumor-tissue sections showed that the tumor tissue of the control group and the combination of 5FU and OXA group comprised spindle-shaped cancer cells. However, the combination of 5-FU and OXA with o-rMETase group had a lower cancer-cell density and extensive necrosis compared to the control and the combination of 5-FU and OXA group. The high efficacy of combination therapy with orMETase is shown histologically (Figure 3).

In the present study, the colon-cancer liver metastasis PDOX mouse model was resistant to the combination of 5FU and OXA, and o-rMETase was able to overcome this resistance.

Our previous studies have shown that o-rMETase had significant efficacy on melanoma, synovial sarcoma and pancreatic cancer PDOX models. The present study demonstrates that combination therapy with o-rMETase can overcome first-line drug resistance of colon-cancer liver metastasis and is a promising clinical strategy for the disease.

Most cancer cells are addicted on MET for their survival. MET-dependent cells synthesize a normal amount of MET; however, they are deficient in S-adenosylmethionine (AdoMET) $(11,22,23)$. Under MET restriction, MET-dependent cancer cells contain low amounts of free MET. It has been suggested that the high MET requirement of cancer cells is due to increased rates of transmethylation compared to normal cells. MET restriction selectively arrests cancer cells in $S / G_{2}$ Phase the cell cycle, thereby blocking cancer cell proliferation $(11,22$, 23). MET restriction therefore sensitizes cancer cells to cytotoxic therapy (24-26). Recently tumor initiating cells were found to be highly MET-dependent (27). Thus, o-rMETase can be potentially used for the treatment of cancer.

\section{Conflicts of Interest}

AntiCancer Inc. uses PDOX models for contract research. QH and YT are employees of AntiCancer Inc. HO, SNY, QH, YT, KM, TH, NS, YK, JHP, ZZ, SR and RMH are or were unsalaried associates of AntiCancer Inc. There are no other competing financial interests.

\section{Authors' Contributions}

Conception and design HO, TH and RMH. Acquisition of data: HO, YT, TK, SNY, TML, QH, YT, KM, TH, NS, YK, JHP, and ZZ, SR. Analysis and interpretation of data: HO, YT, TK, SNY, TML, QH, YT, KM, TH, NS, YK, JHP, ZZ, SR, MB, BC, SRS, FK, KN and RMH. Writing, review, and/or revision of the manuscript: HO, $\mathrm{RMH}$, and SRS.

\section{Acknowledgements}

The paper is dedicated to the memory of AR Moossa, MD; Sun Lee, MD; Professor Li Jiaxi and Masaki Kitajima, MD.

\section{References}

1 Zarour LR, Anand S, Billingsley KG, Bisson WH, Cercek A, Clarke MF, Coussens LM, Gast CE, Geltzeiler CB, Hansen L, Kelley KA, Lopez CD, Rana SR, Ruhl R, Tsikitis VL, Vaccaro GM, Wong MH and Mayo SC: Colorectal cancer liver metastasis: evolving paradigms and future directions. Cell Mol Gastroenterol Hepatol 3(2): 163-173, 2017. PMID: 28275683. DOI: $10.1016 /$ j.jcmgh.2017.01.006

2 Goldberg RM: Advances in the treatment of metastatic colorectal cancer. Oncologist 10: 40-48, 2005. PMID: 16368870. DOI: 10.1634/theoncologist.10-90003-40

3 Misiakos EP, Karidis NP and Kouraklis G: Current treatment for colorectal liver metastases. World J Gastroenterol 17(36): 40674075, 2011. PMID: 22039320. DOI: 10.3748/wjg.v17.i36.4067

4 Hoffman RM: Patient-derived orthotopic xenografts: better mimic of metastasis than subcutaneous xenografts. Nat Rev Cancer 15(8): 451-452, 2015. PMID: 26422835. DOI: $10.1038 / \mathrm{nrc} 3972$

5 Hoffman RM: Development of recombinant methioninase to target the general cancer-specific metabolic defect of methionine dependence: a 40-year odyssey. Expert Opin Biol Ther 15(1): 2131, 2015. PMID: 25439528. DOI: 10.1517/14712598.2015.963050

6 Mecham JO, Rowitch D, Wallace CD, Stern PH and Hoffman RM: The metabolic defect of methionine dependence occurs frequently in human tumor cell lines. Biochem Biophys Res Commun 117(2): 429-434, 1983. PMID: 6661235. DOI: $10.1016 / 0006-291 \times(83) 91218-4$

7 Guo H, Lishko VK, Herrera H, Groce A, Kubota T and Hoffman RM: Therapeutic tumor-specific cell cycle block induced by methionine starvation in vivo. Cancer Res 53(23): 5676-5679, 1993. PMID: 8242623.

8 Hoffman, RM and Jacobsen SJ: Reversible growth arrest in simian virus 40-transformed human fibroblasts. Proc Natl Acad Sci USA 77(12): 7306-7310, 1980. PMID: 6261250. DOI: 10.1073/pnas.77.12.7306 
9 Kokkinakis DM, von Wronski MA, Vuong TH, Brent TP and Schold SC Jr.: Regulation of $O^{6}$-methylguanine-DNA methyltransferase by methionine in human tumour cells. Br J Cancer 75(6): 779-788, 1997. PMID: 9062396. DOI: 10.1038/ bjc.1997.141

10 Hoffman RM and Erbe RW: High in vivo rates of methionine biosynthesis in transformed human and malignant rat cells auxotrophic for methionine. Proc Natl Acad Sci USA 73(5): 1523-1527, 1976. PMID: 179090. DOI: 10.1073/pnas.73.5.1523

11 Wang Z, Yip LY, Lee JHJ, Wu Z, Chew HY, Chong PKW, Teo CC, Ang HY, Peh KLE, Yuan J, Ma S, Choo LSK, Basri N, Jiang X, Yu Q, Hillmer AM, Lim WT, Lim TKH, Takano A, Tan EH, Tan DSW, Ho YS, Lim B and Tam WL: Methionine is a metabolic dependency of tumor-initiating cells. Nat Med 25(5): 825-837, 2019. PMID: 31061538. DOI: 10.1038/s41591-019-0423-5

12 Hoffman RM: The wayward methyl group and the cascade to cancer. Cell Cycle 16(9): 825-829, 2017. PMID: 28318368. DOI: $10.1080 / 15384101.2017 .1304330$

13 Tan Y, Xu M, Tan X, Tan X, Wang X, Saikawa Y, Nagahama T, Sun X, Lenz M and Hoffman RM: Overexpression and largescale production of recombinant L-methionine-alpha-deaminogamma-mercaptomethane-lyase for novel anticancer therapy. Protein Expr Purif 9(2): 233-245, 1997. PMID: 9056489. DOI: 10.1006/prep.1996.0700

14 Takakura T, Ito T, Yagi S, Notsu Y, Itakura T, Nakamura T, Inagaki K, Esaki N, Hoffman RM and Takimoto A: High-level expression and bulk crystallization of recombinant L-methionine gamma-lyase, an anticancer agent. Appl Microbiol Biotechnol 70(2): 183-192, 2006. PMID: 16012835. DOI: 10.1007/s00253-005-0038-2

15 Kawaguchi K, Igarashi K, Li S, Han Q, Tan Y, Miyake K, Kiyuna T, Miyake M, Murakami T, Chmielowski B, Nelson SD, Russell TA, Dry SM, Li Y, Unno M, Eilber FC and Hoffman RM: Recombinant methioninase (rMETase) is an effective therapeutic for BRAFV600E-negative as well as -positive melanoma in patient-derived orthotopic xenograft (PDOX) mouse models. Oncotarget 9(1): 915923, 2018. PMID: 29416666. DOI: 10.18632/oncotarget.23185

16 Kawaguchi K, Miyake K, Han Q, Li S, Tan Y, Igarashi K, Lwin TM, Higuchi T, Kiyuna T, Miyake M, Oshiro H, Bouvet M, Unno $\mathrm{M}$ and Hoffman RM: Targeting altered cancer methionine metabolism with recombinant methioninase (rMETase) overcomes partial gemcitabine-resistance and regresses a patientderived orthotopic xenograft (PDOX) nude mouse model of pancreatic cancer. Cell Cycle 17(7): 868-873, 2018. PMID: 29623758. DOI: $10.1080 / 15384101.2018 .1445907$

17 Igarashi K, Kawaguchi K, Li S, Han Q, Tan Y, Murakami T, Kiyuna T, Miyake K, Miyake M, Singh AS, Eckardt MA, Nelson SD, Russell TA, Dry SM, Li Y, Yamamoto N, Hayashi K, Kimura H, Miwa S, Tsuchiya H, Singh SR, Eilber FC and Hoffman RM: Recombinant methioninase in combination with doxorubicin (DOX) overcomes first-line DOX resistance in a patient-derived orthotopic xenograft nude-mouse model of undifferentiated spindle-cell sarcoma. Cancer Lett 417: 168-173, 2018. PMID: 29306021. DOI: 10.1016/j.canlet.2017.12.028

18 Murakami T, Li S, Han Q, Tan Y, Kiyuna T, Igarashi K, Kawaguchi K, Hwang HK, Miyake K, Singh AS, Nelson SD, Dry SM, Li Y, Hiroshima Y, Lwin TM, DeLong JC, Chishima T, Tanaka K, Bouvet M, Endo I, Eilber FC and Hoffman RM: Recombinant methioninase effectively targets a Ewing's sarcoma in a patient-derived orthotopic xenograft (PDOX) nude-mouse model. Oncotarget 8(22): 35630-35638, 2017. PMID: 28404944 DOI: $10.18632 /$ oncotarget.15823
19 Kawaguchi K, Higuchi T, Li S, Han Q, Tan Y, Igarashi K, Zhao M, Miyake K, Kiyuna T, Miyake M, Ohshiro H, Sugisawa N, Zhang Z, Razmjooei S, Wangsiricharoen S, Chmielowski B, Nelson SD, Russell TA, Dry SM, Li Y, Eckardt MA, Singh AS, Singh SR, Eilber FC, Unno M and Hoffman RM: Combination therapy of tumor-targeting Salmonella typhimurium A1-R and oral recombinant methioninase regresses a BRAF-V600E-negative melanoma. Biochem Biophys Res Commun 503(4): 3086-3092, 2018. PMID: 30166061. DOI: 10.1016/j.bbrc.2018. 08.097

20 Higuchi T, Kawaguchi K, Miyake K, Han Q, Tan Y, Oshiro H, Sugisawa N, Zhang Z, Razmjooei S, Yamamoto N, Hayashi K, Kimura H, Miwa S, Igarashi K, Chawla SP, Singh AS, Eilber FC, Singh SR, Tsuchiya H and Hoffman RM: Oral recombinant methioninase combined with caffeine and doxorubicin induced regression of a doxorubicin-resistant synovial sarcoma in a PDOX mouse model. Anticancer Res 38(10): 5639-5644, 2018. PMID: 30275182. DOI: 10.21873/anticanres.12899

21 Kawaguchi K, Miyake K, Han Q, Li S, Tan Y, Igarashi K, Kiyuna T, Miyake M, Higuchi T, Oshiro H, Zhang Z, Razmjooei S, Wangsiricharoen S, Bouvet M, Singh SR, Unno M and Hoffman $\mathrm{RM}$ : Oral recombinant methioninase (o-rMETase) is superior to injectable rMETase and overcomes acquired gemcitabine resistance in pancreatic cancer. Cancer Lett 432: 251-259, 2018. PMID: 29928962. DOI: 10.1016/j.canlet.2018. 06.016

22 Miyake K, Kiyuna T, Li S, Han Q, Tan Y, Zhao M, Oshiro H, Kawaguchi K, Higuchi T, Zhang Z, Razmjooei S, Barangi M, Wangsiricharoen S, Murakami T, Singh AS, Li Y, Nelson SD, Eilber FC, Bouvet M, Hiroshima Y, Chishima T, Matsuyama R, Singh SR, Endo I and Hoffman RM: Combining tumor-selective bacterial therapy with Salmonella typhimurium a1-r and cancer metabolism targeting with oral recombinant methioninase regressed an Ewing's sarcoma in a patient-derived orthotopic xenograft model. Chemotherapy 63(5):278-283, 2018. PMID: 30673664. DOI: $10.1159 / 000495574$

23 Stern PH and Hoffman RM: Elevated overall rates of transmethylation in cell lines from diverse human tumors. In Vitro 20(8): 663-670, 1984. PMID: 6500606.

24 Stern PH, Wallace CD and Hoffman RM: Altered methionine metabolism occurs in all members of a set of diverse human tumor cell lines. J Cell Physiol 119(1): 29-34, 1984. PMID: 6707100. DOI: $10.1002 /$ jcp.1041190106

25 Stern PH and Hoffman RM: Enhanced in vitro selective toxicity of chemotherapeutic agents for human cancer cells based on a metabolic defect. J Natl Cancer Inst 76(4): 629-639, 1986. PMID: 3457200. DOI: 10.1093/jnci/76.4.629

26 Yano S, Li S, Han Q, Tan Y, Bouvet M, Fujiwara T and Hoffman RM: Selective methioninase-induced trap of cancer cells in $\mathrm{S} / \mathrm{G} 2$ phase visualized by FUCCI imaging confers chemosensitivity. Oncotarget 5(18): 8729-8736, 2014. PMID: 25238266. DOI: 10.18632/oncotarget.2369

27 Joo KM, Jin J, Kim E, Ho Kim K, Kim Y, Gu Kang B, Kang YJ, Lathia JD, Cheong KH, Song PH, Kim H, Seol HJ, Kong DS, Lee JI, Rich JN, Lee J and Nam DH: MET signaling regulates glioblastoma stem cells. Cancer Res 72(15): 3828-3838, 2012. PMID: 22617325. DOI: 10.1158/0008-5472.CAN-11-3760

Received July 11, 2019

Revised July 17, 2019

Accepted July 18, 2019 